\title{
Kinetic Study of the Reaction of Carbon Adsorbents with Oxygen
}

\author{
By William V. Loebenstein, ${ }^{2}$ Leland F. Gleysteen, ${ }^{3}$ and Victor R. Deitz
}

\begin{abstract}
A study was made of the kinetics of oxidation of bone char and other carbon adsorbents. The measurements were limited to temperatures between $250^{\circ}$ and $390^{\circ} \mathrm{C}$. The results were expressed in terms of the fraction of carbon burned per hour at known values of oxygen concentration, temperature, and total rate of flow for activated carbons and bone chars. The rate of oxidation could be expressed either in terms of simple first-order or retarded first-order relationships. A nomograph was used to obtain a rapid estimate of the total fraction of carbon burned at any time for a given rate constant and degree of retardation. The relationship between the reaction-rate constant and the oxygen concentration was linear for a given adsorbent under the same conditions of temperature and flow. Effect of variation in temperature on the rate of oxidation of a new bone char disclosed deviations from the Arrhenius equation even over a 100-deg interval. The influence of time, of oxygen concentration, and of temperature on decarbonization is discussed in relation to the conditions necessary in industrial operations for attaining the optimum uniformity in the carbon content of bone char.
\end{abstract}

\section{Introduction}

A study of the reaction of oxygen with carbon discloses many fundamental problems. Two combustion products, $\mathrm{CO}_{2}$ and $\mathrm{CO}$, are always found simultaneously but in varying relative amounts, depending upon the experimental conditions employed. Heats of adsorption of oxygen on carbon are known to be very high initially but decrease rapidly as the amount of oxygen adsorbed increases. This phenomenon was observed as early as 1924 by Beebe and Taylor $[1]^{4}$ and by Garner and Blench [2]. The large range of activation energies (20 to $70 \mathrm{kcal} / \mathrm{mole}$ ), which have been reported in the literature, may be ascribed to the complex reaction mechanism rather than to particular details in the experimental investigations.

1 This investigation resulted from a joint research project undertaken by the United States Cane Sugar Refiners \& Bone Char Manufacturers, a greater part of the refining industry of the British Commonwealth, and the National Bureau of Standards.

${ }^{2}$ Research Associate at the National Bureau of Standards, representing the cooperating manufacturers.

${ }^{3}$ Present address, Owens Illinois Glass Co., Toledo, Ohio.

${ }_{4}^{4}$ Figures in brackets indicate the literature references at the end of this paper.

Reaction of Carbon Adsorbents with Oxygen
Aside from the theoretical interests in the reaction of oxygen with carbon adsorbents, there is an important practical application. The regeneration of carbon adsorbents, which have been used for the purification of solutions, is accomplished by heating in the presence of a limited amount of oxygen or oxygen-containing gases at elevated temperatures. The heating is intended to remove the adsorbed organic matter by oxidation to volatile compounds and restore as completely as possible the adsorptive properties of the surface.

After the exhaustion of the decolorizing power of carbon adsorbents in the refining of sugars, it has been demonstrated that it is technically possible to regenerate almost all kinds of carbon adsorbents. However, there are large differences in the loss of weight realized during regeneration of adsorbents of different origin. This has an important bearing on the economic feasibility of the regeneration. The results given in this paper indicate a striking difference in the magnitude of the rates of oxidation of bone chars and of the activated carbons. 
The raw materials from which carbon adsorbents are prepared vary considerably. The final products may be viewed as carbonaceous residues of varying stability resulting from a destructive distillation of the raw material followed by a limited oxidation under variously controlled conditions. The physical and chemical properties of these residues vary and, consequently, the exact specification of such residues is extremely difficult. The reproducibility of a particular product derived from a given raw material is not too easily maintained even when the requirements of a commercial application are considered. It is necessary, therefore, in order to meet the exact requirements of fundamental research, that the desired experiments be made with aliquot parts of a well-mixed sample. The materials used in obtaining the results reported in this paper have been so prepared. Data on activated carbons and new bone char are reported in this paper. The results for spectroscopically pure graphite and spent bone char are also given for comparison purposes.

In the experiments described in this paper the reaction is studied under conditions that maintain a large excess of oxygen in the gaseous phase compared to that consumed in the oxidation. By studying the reaction with respect to the carbon consumed it is possible to focus attention on the regeneration process.

\section{Experimental Procedure}

The sample for reaction with oxygen was supported in a vertical tube with inlet for the gas mixtures at the top and the outlet at the bottom. This tube was $15 \mathrm{~mm}$ in diameter and $40 \mathrm{~mm}$ high and held samples varying in amounts from 0.5 to $5.0 \mathrm{~g}$. It was constructed of fused silica for the graphite experiments and of Pyrex glass for the carbon adsorbents. In order to insure uniform conduction of heat the reaction tube was fitted snugly into a cylindrical brass block $150 \mathrm{~mm}$ tall and $75 \mathrm{~mm}$ in diameter. This whole assembly was contained in a vertically mounted cylindrical furnace with a control thermocouple placed close to the windings of the furnace. A second thermocouple was fitted into the center of the brass block through a hole situated so that the junction lay as close as possible to the outside wall of the reaction tube in the vicinity of the sample.
The reacting gas mixtures contained in gas cylinders consisted of known percentages of oxygen in nitrogen. The compositions had been determined by the Gas Chemistry Section of this Bureau. Purified nitrogen was passed through the reaction tube during the preliminary heating interval. The flow of nitrogen was discontinued by the employment of a three-way stopcock ahead of the reaction tube at the same instant that the oxygen mixture was introduced. Intervals of time were measured from this moment. The gas mixture was metered into the system at $91 \mathrm{ml} / \mathrm{min}$ by means of a flowmeter and maintained at this rate throughout the entire run.

Preliminary tests showed that the water vapor contained in the exit gases, in comparison with the carbon dioxide and carbon monoxide, was so small that it could be neglected entirely. U-tubes of Ascarite-Anhydrone were used in the absorption train to determine carbon dioxide. At the end of each predetermined time interval, one tube was removed from the train and a second tube of the same dimensions immediately inserted. The side arms of the U-tube were bent downward so as to fit into mercury-seal couplings and thus maintain airtight connections. The replacement of the tared U-tubes required but a few seconds. By alternating the twin U-tubes in this manner, it was possible to follow the course of the combustion by gravimetric determination without interrupting the conditions of flow and yet have a quantitative cumulative measurement. The remaining gases, which contained residual oxygen and carbon monoxide along with nitrogen, were next passed through a hopcalite catalyst, which converted the carbon monoxide quantitatively to carbon dioxide. This, in turn, was determined gravimetrically by means of a pair of $U$-tubes of Ascarite-Anhydrone in exactly the same manner as for the carbon dioxide.

Each sample, prior to its controlled combustion, was heated to constant weight at $110^{\circ} \mathrm{C}$ in an atmosphere consisting either of helium or purified nitrogen [3].

The constancy of temperature during a combustion was maintained manually for periods of 8 hours or less and by automatic means for longer periods of time. In the latter case, an indicating potentiometer controller was employed. Manually, it was possible to hold a desired temperature 
to within less than $\pm 1 \mathrm{deg}$ C. A temperature control of about $\pm 3 \mathrm{deg} \mathrm{C}$ was readily attainable by automatic means.

The total weight of carbon burned was computed from the yields of carbon dioxide and carbon monoxide. The rate of reaction was expressed as that fraction, $f$, of the initial carbon present in the sample which burned per hour. No attempt is made in this present treatment to interpret individually the amounts of carbon dioxide and carbon monoxide produced.

The rate of flow during the experiments was chosen so that the oxygen concentration was not significantly decreased by its consumption. Furthermore, the residual oxygen concentration was sufficient for the quantitative oxidation of the carbon monoxide to carbon dioxide. This is a necessary requirement in the analysis of the gaseous reaction products. Moreover, it was thought that by keeping the oxygen in excess, the interpretation of the reaction mechanism might be simplified. The oxygen concentration in the exit gases was verified later with a specially calibrated Pauling oxygen meter.

\section{Kinetics of the Reactions}

The rate of combustion is expressed throughout this paper with respect to carbon. The control of the carbon content of bone char during the revivification process is of vital importance in char house operations of sugar refineries. Hence, the study of the combustion with respect to carbon lends itself most readily to practical interpretations.

If the over-all combustion is of the first order with respect to carbon, the rate at which carbon burned should be proportional to the fraction of the carbon remaining, thus

$$
\frac{d f}{d t}=k(1-\dot{f}),
$$

where $f$ is the fraction of initial carbon burned in $t$ hours and $k$ is the constant of proportionality (reaction rate constant). Upon integration, eq 1 becomes

$$
2.303 \log _{10} \frac{1}{1-f}=k t,
$$

with the constant of integration vanishing upon substitution of the initial conditions that $f$ is zero when $t$ is zero. It will be seen from figures 1 and

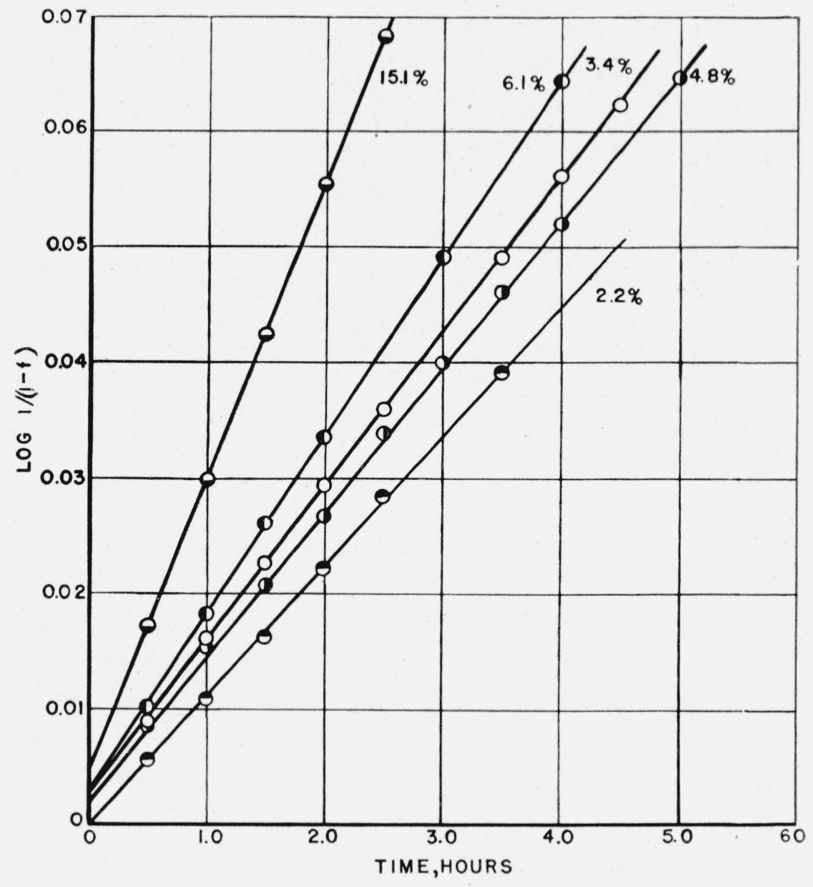

Figure 1. Reaction of activated carbon 6 with varying oxygen concentrations.

The ordinate is $\log _{10} 1 /(1-f)$, where $f$ is the fraction of carbon oxidized. The abscissa is the time in hours. The rate of flow is $91 \mathrm{ml} / \mathrm{min}$. and the temperature is $390^{\circ} \mathrm{C}$.

2 that a linear plot of $\log 1 /(1-f)$ against $t$ applies to graphite and the activated carbons, but not to any of the bone chars investigated.

The combustion of bone chars will be shown to obey a retarded first-order relationship identical in form with that proposed by C. N. Hinshelwood [4] for the kinetics of the catalytic decomposition of nitrous oxide, in which it was assumed that the reaction was retarded by the oxygen produced. This does not necessarily imply that the retardation in the combustion of bone chars can be attributed to a similar mechanism.

In the present treatment, the differential equation for combustion of bone chars may be written as follows:

$$
\frac{d f}{d t}=\frac{k(1-f)}{1+b f},
$$

where the constant $b$ is a measure of the degree of retardation during a given combustion. This is also similar to an equation suggested by J. D. Lambert [5] for the oxidation of charcoal where the reaction was investigated with respect to oxygen consumed. It can be seen from eq 3 that if no 


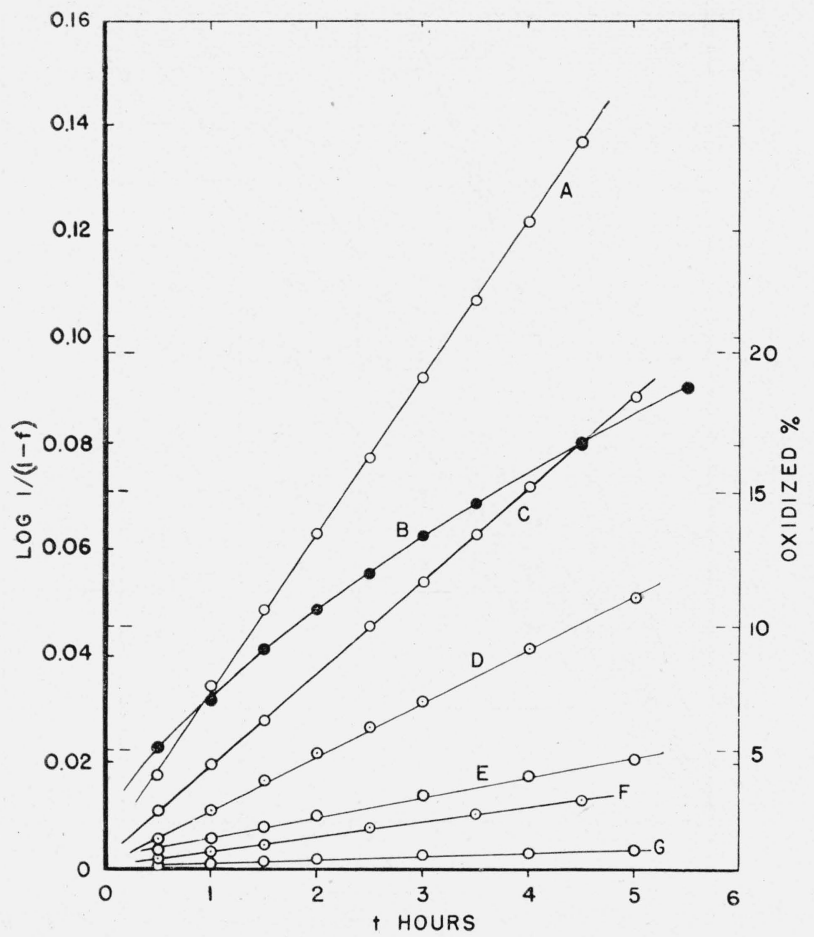

Figure 2. Oxidation of carbon adserbents and graphite in 6.1 percent of oxygen and a rate of flow of $91 \mathrm{ml} / \mathrm{min}$.

The left ordinate scale is $\log _{10} 1 /(1-f)$, where $f$ is the fraction of carbon oxidized, and the right ordinate seale is percentage oxidized $(100 f) . \quad \mathrm{A}$, Carbon 5 $\left(390^{\circ} \mathrm{C}\right) ; \mathrm{B}$, bone char $2\left(280^{\circ} \mathrm{C}\right)$; C, carbon $6\left(390^{\circ} \mathrm{C}\right) ; \mathrm{D}$, graphite $\left(711^{\circ} \mathrm{C}\right)$; $\mathrm{E}$, carbon $4\left(390^{\circ} \mathrm{C}\right)$; F, graphite $\left(600^{\circ} \mathrm{C}\right)$; G, carbon $4\left(320^{\circ} \mathrm{C}\right)$.

retardation exists, $b$ becomes zero and the expression reverts to the special case of eq 1 . It is also apparent, even with a finite value of $b$ other than zero, that the limiting: value of eq 3 as $f$ approaches zero is the same as eq 1. Equation 3, upon integration, yields

$$
\frac{1}{t} \ln \frac{1}{1-f}=\frac{b}{1+b} \frac{f}{t}+\frac{k}{1+b},
$$

which may be used by plotting $1 / t \ln [1 /(1-f)]$ against $f / t$ to determine both $k$ and $b$. Equation 4 may be rearranged, however, into the form

$$
\frac{1}{t} \ln \frac{1}{1-f}=k-b \frac{1}{t}\left[\left(\ln \frac{1}{1-f}\right)-f\right],
$$

which lends itself more readily to a direct evaluation of $b$ and $k$, since these two quantities emerge immediately from the slope and intercept, respectively.

\section{Application of Simple First-Order Ki- netics to Carbon Adsorbents Other Than Bone Char}

Table 1 lists the values of $f$ computed at the periods of time indicated during the course of five experiments with different samples of the same activated carbon 6 . Each of the five experiments was conducted with a different percentage of oxygen in nitrogen, as listed in the first column. All five combustions were performed at the same temperature, $390^{\circ} \mathrm{C}$, and at the same rate of flow of reactant gases, $91 \mathrm{ml} / \mathrm{min}$. The data from table 1 are plotted in figure 1 . The corresponding values of $k$ computed from the slopes of these lines are recorded in the last column of table 1 . Additional curves are presented in figure 2 for activated carbons 4, 5, and 6 . Some results are also included for samples of spectroscopically pure graphite at $600^{\circ}$ and $711^{\circ} \mathrm{C}$.

\section{TABLE 1. Combustion of an activated carbon}

[Reaction of activated carbon 6 with different oxygen-nitrogen mixtures at $390^{\circ} \mathrm{C}$ and $91 \mathrm{ml} / \mathrm{min}$ flow showing the variations in the fraction of carbon

\begin{tabular}{|c|c|c|c|c|c|c|c|c|c|c|c|}
\hline \multirow{2}{*}{$\begin{array}{l}\text { Oxy- } \\
\text { gen }\end{array}$} & \multicolumn{10}{|c|}{ Fraction burned at (hours) - } & \multirow{2}{*}{$\begin{array}{c}\text { Rate } \\
\text { con- } \\
\text { stant, } \\
k \\
\text { (cal- } \\
\text { cu- } \\
\text { lated) }\end{array}$} \\
\hline & 0.5 & 1.0 & 1.5 & 2.0 & 2.5 & 3.0 & 3.5 & 4.0 & 4.5 & 5.0 & \\
\hline $\begin{array}{l}\text { Per- } \\
\text { cent }\end{array}$ & & & & & & & & & & & \\
\hline $2.2 \ldots$ & 0.0129 & 0.0246 & 0.0367 & 0.0496 & 0.0630 & & 0.0863 & & 0.113 & & 0.026 \\
\hline $3.4 \ldots$ & .0203 & .0363 & .0511 & .0656 & .0796 & & .107 & 0.120 & .134 & & .031 \\
\hline $4.8 \ldots$ & .0197 & .0347 & .0468 & .0596 & .0749 & 0.0878 & .101 & .113 & & 0.139 & .029 \\
\hline $6.1 \ldots$ & .0231 & .0413 & .0583 & .0745 & …... & .107 & & .138 & & & .036 \\
\hline $15.1 \ldots$ & .0388 & .0665 & .0930 & .120 & .146 & & & & & & .060 \\
\hline
\end{tabular}
burned, $f$, with time]

\section{Application of Retarded First-Order Kinetics to Bone Char}

When values of $\log 1 /(1-f)$ were plotted against $t$ for bone chars, the resulting graphs were never linear, but invariably showed a marked curvature, which was concave to the time axis. Such a curve for a typical bone char (char 2 at $280^{\circ} \mathrm{C}$ ) is shown in figure 2 (filled-in circles) as compared to other activated carbons and graphite (open circles). Even in some of the latter cases a slight deviation from linearity is apparent, although the effect is not nearly as marked. The percentage of the original carbon oxidized at any time, $t$, for each of the experiments plotted on figure 2 can be estimated by reference to the vertical axis at the right. 
Before attempting to apply the concepts of retarded first-order kinetics (eq 4 and 5) to the experimental data, it is necessary that zero time be known with more precision. One reason for this is that the time variable occurs in both coordinates of the proposed graphs for testing eq 4 and 5. Although this complication did not exist in the simple first-order test as given in eq 2 , a close examination of figures 1 and 2 will disclose that even in this case most of the lines do not pass through the origin. The displacement of these lines to the left of the origin in figure 1 may be due to the presence of chemisorbed oxygen in the samples. This remains despite the preliminary heating in pure nitrogen prior to the introduction of gaseous oxygen. There is also a tendency to displace the lines to the right of the origin. This is due to the dilution of the reaction mixture with the pure nitrogen and the time lag involved in sweeping out the dead space. The actual displacement observed suggests the dominating effect of chemisorbed oxygen.

It is possible to avoid these errors by computing a steady-state zero time from the original data for each experiment with bone char. The beginning of the steady-state condition was made to agree with a time at which the Ascarite-Anhydrone tubes were changed early in the experiment.

Figure 3 is a typical plot of data obtained for the controlled combustion of a sample of new bone char 2 according to eq 4 after corrections ${ }^{5}$

5 The weight of carbon, $\Delta w$, burned up to this time was subtracted from the original weight of the sample and also subtracted from the original weight of carbon, $W$, present in the sample. In the same manner, $\Delta w$ was subtracted from the accumulative weights of carbon burned, $w$, subsequent to this time in order to get the corresponding accumulative steady-state values. The steady-state fraction $f$, can then be expressed by the relationship $(w-\Delta w) /(W-\Delta w)$.

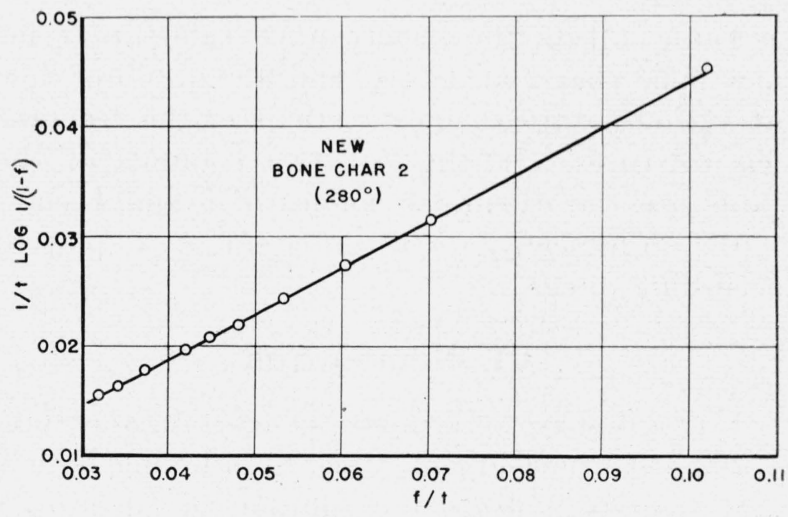

Figure 3. Oxidation of new bone char 2 in 6.1 percent of oxygen and at $91 \mathrm{ml} / \mathrm{min}$.

The abscissa is $f / t$ and the ordinate $1 / t \log [1 /(1-f)]$, where $f$ is the fraction of carbon oxidized, and $t$ is the time in hours.

had been made for steady-state conditions. A similar illustration for a spent bone char (char 15) is given in figure 4.

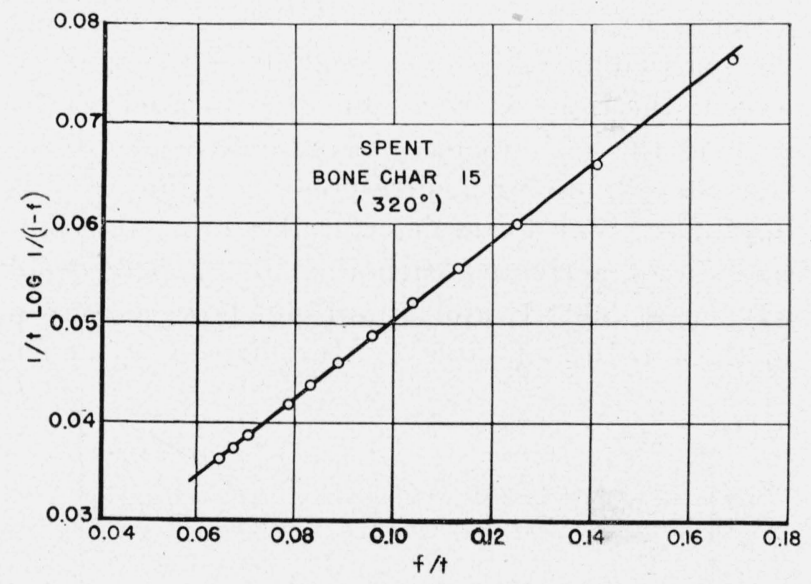

Figure 4. Oxidation of spent bone char 15 in 6.1 percent of oxygen and at $91 \mathrm{ml} / \mathrm{min}$.

The plot is similar to that in figure 3 .

TABLE 2. Combustion of a bone char

[Reaction of new bone char 2 with different oxygen-nitrogen mixtures at $280^{\circ} \mathrm{C}$ and $91 \mathrm{ml} / \mathrm{min}$ flow showing the variations in the fraction of carbon burned with time. The data are referred to steady-state conditions for each combustion.]

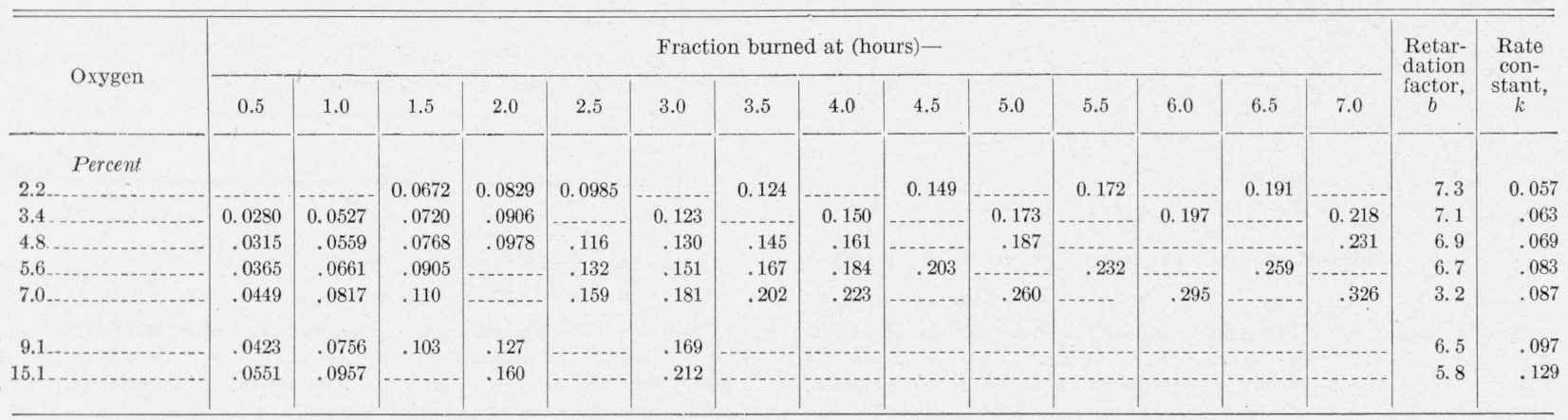


Table 2 lists the steady-state values of $f$ for new bone char 2 at $280^{\circ} \mathrm{C}$ and $91 \mathrm{ml} / \mathrm{min}$ of flow at various oxygen concentrations of the reactant gas mixtures. In the last two columns of the table are the calculated values of $b$ and $k$ computed graphically when the data were plotted according to eq 5 .

\section{Nomograph}

If it is desired to estimate the fraction of carbon $f$ that is burned at any time, $t$, assuming both $b$ and $k$ to be known, the solution of eq 4 or 5 becomes rather laborious. By the use of a nomograph, however, this may be accomplished in a matter of seconds. Such a nomograph has been constructed, figure 5, which may be utilized for any first-order combustion described in this paper regardless of the temperature, oxygen concentration, rate of flow, or degree of retardation. A straight edge is laid across the sheet connecting the particular value of $b$ located on the vertical axis at the right with a value of $k t$ located on the scale at the left. Where this straight edge crosses the curved line the corresponding value of $f$ is obtained. For example, consider first the combustion of activated carbon 6 in 2.2 percent of oxygen at $390^{\circ} \mathrm{C}$ and $91 \mathrm{ml} / \mathrm{min}$ flow, as shown in the top row of table 1 . In this case $k=0.026$

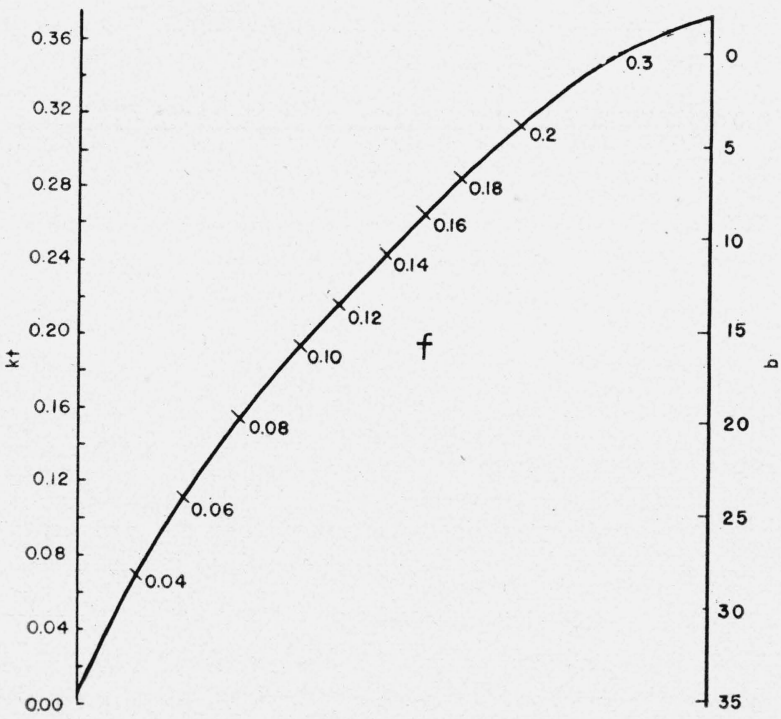

Figure 5. Nomograph for the rapid solution of equation 4 or 5 .

The left vertical scale is expressed in units of $k t$, where $k$ is the reaction rate constant (initial fraction of carbon burned per hour), and $t$ is the time in hours. The right vertical scale is given in terms of $b$, the degree of retardation. The intermediate scale is in units of $f$, the fraction of carbon burned. and $b=0$. Since it is desired to estimate the fraction of carbon burned after $4.5 \mathrm{hr}, k t=4.5 \times 0.026=$ 0.117 . The nomograph gives directly an $f$-value of 0.11 . This compares quite well with the $4.5-\mathrm{hr}$ value of $f$ (table 1 ), which is 0.113 .

As a second example, consider the combustion of new bone char 2 in 3.4 percent of oxygen at $280^{\circ} \mathrm{C}$ and $91 \mathrm{ml} / \mathrm{min}$ flow. These data are found in the second row of table 2. In this case $b$ and $k$ were calculated to be 7.1 and 0.063 , respectively. It may be of interest to estimate the fraction of carbon which would be expected to burn in $1 \mathrm{hr}$ under this particular set of conditions. For $t=1$, $k t=0.063$, and the nomograph gives an $f$-value of 0.052 . The corresponding value of $f$ in table 2 is 0.0527 . It is thus seen that the nomograph has an exceedingly wide range of applicability. It is possible to extend either or both of the vertical axes in order to accommodate still larger values of $b$ and $k$, since each of these two axes is marked off in a linear scale.

\section{Influence of Oxygen Concentration and Temperature on the Oxidation of Some Carbon Adsorbents}

When the specific reaction rate constant $k$ was plotted against the corresponding oxygen percentage in the reaction mixture under the same conditions of temperature and rate of flow, the resulting points were again best correlated by a linear relationship. Curve $A$ in figure 6 shows the dependency of $k$ upon oxygen percentage in the

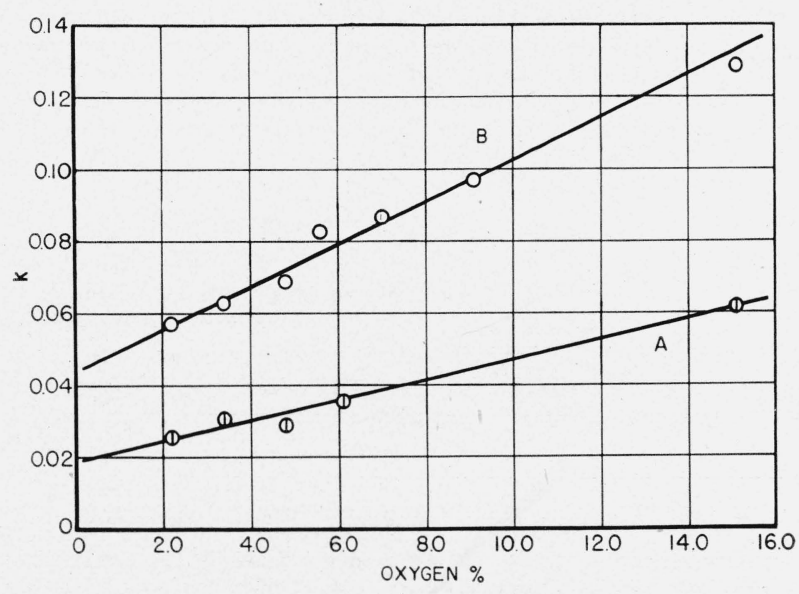

Figure 6. Rate constant $k$ as a function of oxygen concentration.

The line $\mathbf{A}$ is for the oxidation of activated carbon 6 at $91 \mathrm{ml} / \mathrm{min}$ flow and $390^{\circ} \mathrm{C}$ (see table 1 ). Line B is for the oxidation of new bone char 2 at 91 $\mathrm{ml} / \mathrm{min}$ flow and $280^{\circ} \mathrm{C}$ (see table 2). The ordinate is the rate constant $k$, and the abscissa is the oxygen percentage. 
TABLE 3. Combustion of a new bone char in 6.1 percent of oxygen in nitrogen at a total velocity of $91 \mathrm{ml} / \mathrm{min}$. The data are referred to steady-state conditions for each combustion.

\begin{tabular}{|c|c|c|c|c|c|c|c|c|c|c|c|c|c|c|c|}
\hline \multirow{2}{*}{ Temperature, ${ }^{\circ} \mathrm{C}$} & \multicolumn{13}{|c|}{ Fraction burned at (hours) - } & \multirow{2}{*}{$\begin{array}{l}\text { Retarda- } \\
\text { tion } \\
\text { factor, } b\end{array}$} & \multirow{2}{*}{$\begin{array}{l}\text { Rate con- } \\
\text { stant, } k\end{array}$} \\
\hline & 0.5 & 1.0 & 1.5 & 2.0 & 2.5 & 3.0 & 3.5 & 4.0 & 4.5 & 5.0 & 5.5 & 6.0 & 6.5 & & \\
\hline $250 \ldots$ & 0.0106 & 0.0199 & 0.0274 & & 0.0416 & & 0.0564 & & 0.0664 & & 0.0772 & & 0.0861 & 13.5 & 0.0224 \\
\hline $280 \ldots$ & - . . . & .0417 & .0580 & 0.0727 & .0874 & 0.100 & & 0.123 & & 0.144 & ........ & 0.164 & & 7.9 & .0495 \\
\hline 320 & .0843 & .144 & .190 & .228 & .260 & (n) & & - n & & (n) & & 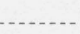 & & 6.0 & .221 \\
\hline 325 & .0860 & .151 & .200 & - & .277 & .310 & $-\ldots$ & .364 & & & & & & 5.3 & .231 \\
\hline
\end{tabular}

reaction mixture for the combustion of activated carbon 6. The data used for this graph were obtained from the first and last columns of table 1 . Curve $B$ was constructed in the same manner by using the data for new bone char 2 as given in table 2. The fact that neither of these lines appears to intersect the origin of coordinates is quite striking. The magnitude of this deviation is greater than can apparently be accounted for on the basis of experimental error.

The reaction rate constant for the combustion of a new bone char was determined at four temperatures within the range of $250^{\circ}$ to $325^{\circ} \mathrm{C}$. In each case the reactant gas consisted of 6.1 percent of oxygen in nitrogen flowing at a total velocity of $91 \mathrm{ml} / \mathrm{min}$. It was not practical under the conditions employed to exceed this range of temperatures. When this was attempted, the combustion proceeded either too rapidly to obtain reliable measurements or too slowly to insure constancy of conditions over the period of time required to obtain measurable differences in weight. The steady-state values of the fraction of carbon burned at each interval of time are recorded in table 3 . Corresponding values of $k$. and $b$ computed from eq 5 are also tabulated for each of these temperatures.

The dependence of $k$ on temperature is usually expressed by the well-known Arrhenius equation

$$
\ln k=-E / R T+\ln k_{0},
$$

where $E$ is the activation energy (or free energy of activation), $R$ the gas constant, and $k_{0}$ is a constant. Figure 7 shows that the logarithm of $k$ when plotted against the reciprocal of the absolute temperature, gave a smooth curve, which was slightly convex to the $1 / T$ axis. An over-all activation energy (or free energy) computed from the slope of this curve would seem to vary between 15 and $35 \mathrm{kcal}$ under the conditions of these

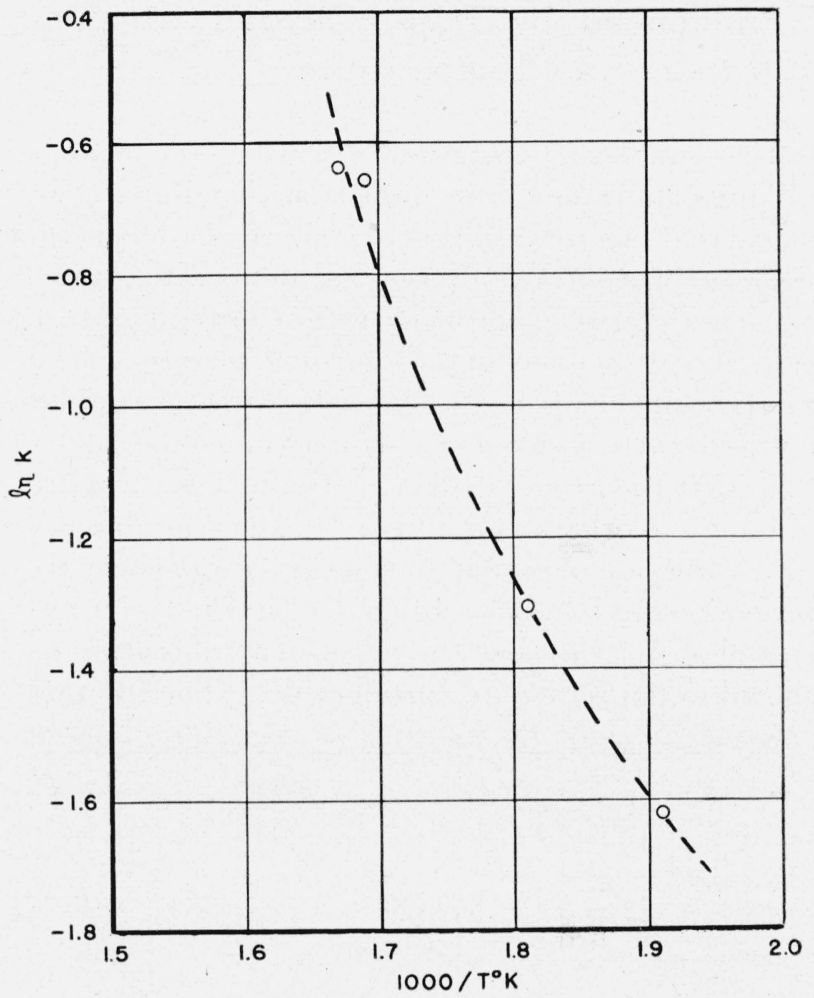

Figure 7. A plot of $\ln k$ against 1/T for new bone char 2 , where $T$ is the absolute temperature.

experiments. However, the deviation from linearity definitely points to the need for further investigation before any reliable interpretations are to be made concerning this apparent anomaly. Also, the physical significance of the parameter $b$ along with its dependency upon the other variables present is beyond the scope of this paper. However, there is no doubt that the reaction rate does depend more or less exponentially upon $1 / T$.

Other combustion experiments in which only the rate of flow of reactant gas mixture was varied by a twofold factor or more seemed to have very little effect upon the reaction rate constant. Furthermore, the weight of the sample was varied under 
otherwise identical conditions from one combustion experiment to another, yet the total fraction of carbon burned at each of the similar time intervals remained constant. These results, together with the linear effect of oxygen concentration upon the combustion rate, form a fairly complete picture as to the various effects of each factor.

\section{Decarbonization of Bone Char as Influenced by Time, Oxygen Concen- tration, and Temperature}

Uniform decarbonization of service bone char is an important factor in industrial installations in sugar refining [6]. In practice, methods to control decarbonization have entailed deliberate variations in time, oxygen concentration, or temperature that were involved in the burning process. The relative effects of changes in each of these variables are illustrated in figure 8 . It may be seen in figure 8 , a, that the rate of oxidation diminishes. Figure 8 , b, on the other hand, illustrates that the changes in the fraction of carbon burned are always directly proportional to increases in the oxygen concentration. In contrast, the effect of temperature as shown in figure 8 , c, is considerable. The fraction
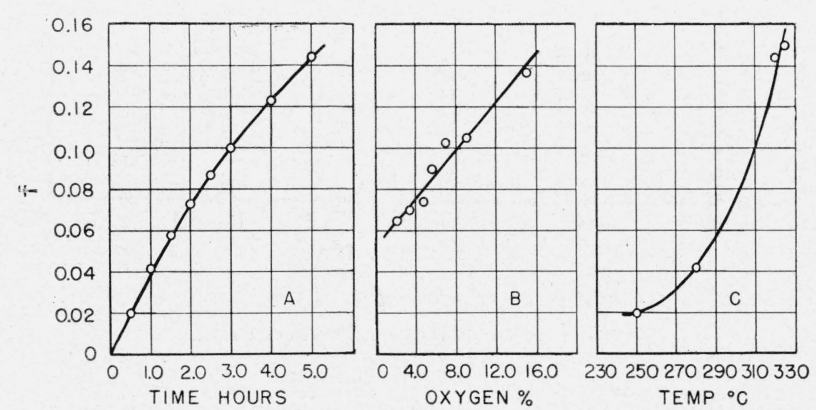

FIGURE 8. Influence of time, oxygen concentration, and temperature on decarbonization of a bone char.

The ordinate scale common to the three curves is given in terms of $f$. The abscissa of curve $\mathrm{A}$ is in hours $\left(6.1 \%\right.$ of $\left.\mathrm{O}_{2}, 280^{\circ} \mathrm{C}, 91 \mathrm{ml} / \mathrm{min}\right)$; that of curve $\mathrm{B}$ is in percentage of $\mathrm{O}_{2}\left(1.5 \mathrm{hr}, 280^{\circ} \mathrm{C}, 91 \mathrm{ml} / \mathrm{min}\right)$; that of curve $\mathrm{C}$ is the temperature ${ }^{\circ} \mathrm{C}\left(1.0 \mathrm{hr}, 6.1 \%\right.$ of $\left.\mathrm{O}_{2}, 91 \mathrm{ml} / \mathrm{min}\right)$.

of carbon burned becomes progressively more and more sensitive to changes in temperature as the latter increases.

It is thus seen that temperature is by far the most important single factor in influencing the extent of decarbonization. The temperature range investigated in the laboratory is appreciably lower than the peak temperatures $\left(400^{\circ}\right.$ to $\left.500^{\circ} \mathrm{C}\right)$ realized in industrial operations. At these high temperatures it was impossible to measure the exceedingly high rates of combustion with the apparatus described. An extrapolation from the data in the temperature range $250^{\circ}$ to $325^{\circ}$ to $400^{\circ} \mathrm{C}$ or higher may be seen not to be feasible from either figure 7 or 8 , c.

Some quantitative comparisons regarding the conditions affecting the variation in the fraction of carbon burned are evident in the contents of table 4. There are two ranges of $f$-values, which have immediate application to refinery practice. In a single cycle of regeneration with the conventional kiln, less carbon is to bè removed than in a single passage through a decarbonizer. In the first case the order of magnitude of the change in $f$ is 0.02 to 0.03 ; in the second case it may be as high as 0.13 to 0.14 . In order to realize the desired carbon removal by adjustment in temperature alone $(1.0 \mathrm{hr}, 6.1 \%$ of oxygen, and 91 $\mathrm{ml} / \mathrm{min}$ ), it is necessary to maintain a temperature of $260^{\circ}$ and $320^{\circ} \mathrm{C}$, respectively. While a fluctuation of $\pm 10.5 \mathrm{deg}$ can be permitted at the low temperature for the desired carbon removal, a no greater variation than $\pm 1.0 \mathrm{deg}$ is allowed at $320^{\circ}$ C. Correspondingly, to obtain the desired decarbonization by adjustment of oxygen concentration alone $\left(1.5 \mathrm{hr}, 280^{\circ} \mathrm{C}\right.$, and $\left.91 \mathrm{ml} / \mathrm{min}\right)$, it is necessary to hold the concentration within the range of \pm 0.85 percent in either case. Finally, to obtain the decarbonization by adjustment of the time factor alone $\left(6.1 \%\right.$ of oxygen, $280^{\circ} \mathrm{C}$, and $91 \mathrm{ml} / \mathrm{min}$ ), it is necessary to heat the char for 0.6 and $4.5 \mathrm{hr}$, respectively. A fluctuation of only $\pm 7 \mathrm{~min}$ is permitted at the lower time, while as much as $\pm 15 \mathrm{~min}$ may be tolerated at the higher time.

These results definitely point to the following criteria for uniform decarbonization: (1) long reaction times, (2) low temperatures, and (3) whatever concentrations of oxygen are required to give the desired decarbonization. A rough visual indication of such uniformity is evidenced by the 
absence of the familiar black and white appearance of decarbonized char which is observed in most refinery operations. A more precise estimate of uniformity requires numerous laboratory analyses. There is an additional advantage in low-temperature operation based on considerations of the liberation of the heat of combustion. Temperature control is dependent upon an adequate dissipation of this heat which, in turn, de-

TABLE 4. Conditions affecting fluctuations in $f$

\begin{tabular}{|c|c|c|c|c|}
\hline \multirow{2}{*}{$\begin{array}{l}\text { Assumed } \\
\text { range of } f\end{array}$} & \multicolumn{4}{|c|}{$\begin{array}{c}\text { Permissable deriation of any one } \\
\text { variable }\end{array}$} \\
\hline & Time & $\begin{array}{l}\text { Oxygen } \\
\text { enncen- } \\
\text { tration }\end{array}$ & Teny & ature \\
\hline $\begin{array}{l}0.02 \text { to } 0.03 \\
.13 \text { to } .14\end{array}$ & $\begin{array}{c}c h \\
\pm 0.125 \\
\pm .250\end{array}$ & $\begin{array}{l}\text { Fercent } \\
\pm 0.85\end{array}$ & $\begin{array}{l}{ }^{\circ} \mathrm{C} \\
\pm 10.5 \\
\pm 1.0\end{array}$ & $\begin{array}{r}{ }^{\circ} F \\
\pm 18.9 \\
\pm 1.8\end{array}$ \\
\hline
\end{tabular}

pends upon the heat transfer away from the char. Because of the poor heat conductivity of char, the necessary heat transfer is obtained only at the low temperatures, where the heat of combustion per unit time can be kept at a minimum.

\section{References}

[1] R. A. Beebe and H. S. Taylor, J. Am. Chem. Soc. 46, 43 (1924).

[2] W. E. Garner and E. A. Blench, J. Chem. Soc. (London) 125, 1288 (1924).

[3] V. R. Deitz and L. F. Gleysteen, J. Research NBS 28, 795 (1942) RP1479.

[4] C. N. Hinshelwood, Kinetics of chemical change, p. 192 (Oxford Univ. Press, Oxford, Eng., 1947).

[5] J. D. Lambert, Trans. Faraday Soc. 32, 1584 (1936).

[6] V. R. Deitz, Preliminary survey of bone char revivification and filtration, Bone char research project at National Bureau of Standards, Special Report (1947).

Washington, August 27, 1948. 